\title{
The origin of urinary aromatic compounds excreted by ruminants 1. The metabolism of quinic, cyclohexanecarboxylic and non-phenolic aromatic acids to benzoic acid
}

\author{
BY A. K. MARTIN \\ Hannah Research Institute, Ayr, Scotland KA6 5HL \\ (Received 12 January 1981-Accepted 14 August 1981)
}

\begin{abstract}
1. The contribution of dietary constituents to the large urinary output of benzoic acid characteristic of ruminants and some herbivores is not well understood.

2. Methods for the analysis of quinic, cyclohexanecarboxylic, benzoic, phenylacetic, 3-phenylpropionic and cinnamic acids in urine and in rumen fluids were developed.

3. The urinary output of aromatic acids by sheep given seven rations was determined : benzoic acid output varied between 2.8 and $7.8 \mathrm{~g} / \mathrm{d}$; phenylacetic acid output between 0.16 and $1.3 \mathrm{~g} / \mathrm{d}$; cinnamic acid between 0.08 and $0.25 \mathrm{~g} / \mathrm{d}$ and small amounts of 3 -phenylpropionic acid were found in some samples.

4. Increments in urinary aromatic acid excretion were determined when the acids listed in paragraph 2 were infused via rumen or abomasal cannulas.

5. When cyclohexanecarboxylic acid was infused $40 \%$ of the dose was excreted as urinary benzoic acid after either route of infusion. Quinic acid was completely metabolized in the rumen; following rumen infusion between 16 and $53 \%$ of the infused acid was recovered as urinary benzoic acid; none was so recovered after abomasal infusion.

6. Urinary recoveries of rumen- and abomasally-infused aromatic acids were: benzoic acid 90 and $88 \%$ respectively as benzoic acid, phenylacetic acid 78 and $83 \%$ respectively as phenylacetic acid, 3-phenylpropionic acid 96 and $105 \%$ respectively as benzoic acid and cinnamic acid, 70 and $70 \%$ respectively as benzoic acid.

7. The concentration of aromatic acids in rumen fluid varied with time after feeding: cyclohexanecarboxylic acid was maximal $(7 \mathrm{mg} / \mathrm{l}) 1 \mathrm{~h}$ after feeding, benzoic acid was always a minor component $(0.5 \pm 0.5 \mathrm{mg} / 1)$, phenylacetic acid varied between 0 and $35 \mathrm{mg} / \mathrm{l}$ and 3-phenylpropionic acid between 25 and $47 \mathrm{mg} / \mathrm{l}$. Cinnamic acid was not found in rumen fluid but on rumen infusion of this acid the concentration of 3-phenylpropionic acid in rumen fluid increased by $10 \mathrm{mg} / \mathrm{l}$ rumen fluid per $\mathrm{g}$ infused per $\mathrm{d}$.

8. The incomplete metabolism of quinic and cyclohexanecarboxylic acids to urinary benzoic acid is discussed. It is concluded that the principal dietary precursors of urinary benzoic acid in ruminants are compounds yielding 3-phenylpropionic acid on microbial fermentation in the rumen. The small amount of cinnamic acid characteristic of ruminant urine arises as an intermediate in the $\beta$-oxidation of 3-phenylpropionic acid in the body tissues.
\end{abstract}

Herbivores have long been known to excrete large quantities of aromatic acids in their urine. The principal aromatic acids excreted in ruminant urine are hippuric and phenaceturic acids which are respectively the glycine conjugates of benzoic and phenylacetic acids. The quantities of these acids excreted by sheep have been studied in this laboratory (Martin, $1969 a$; Martin, 1970) and their dietary origin established (Martin, 1969b). The major source of urinary phenylacetic acid has been found to be rumen catabolism of phenylalanine (Scott et al. 1964; Patton \& Kesler, 1967; Martin, 1973). However, the origin of the principal aromatic acid, benzoic acid, remains to be established. Many suggestions have been made for the possible identity of benzoic acid precursors in ruminant forages; these include the alcohol-soluble precursors of lignin (Brigl \& Pfähler, 1929), lignin (Pazur \& DeLong, 1948) and fibre (Schiemann et al. 1965). Alicyclic acids such as quinic acid (1,3,4,5-tetrahydroxycyclohexanecarboxylic acid) are widely distributed in plants and are to a varying extent excreted in the urine of mammals as benzoic acid: the proportion excreted in this form depends on the extent of microbial metabolism in the digestive tract (Adamson et al. 1970).

Rumen microbial metabolism of alicyclic acids might then be expected to yield large urinary increments of benzoic acid. Cyclohexanecarboxylic acid is a product of intestinal microbial metabolism of shikimic (3,4,5-trihydroxycyclohex-I-ene-carboxylic acid; Brewster 
Table 1. Expt 1-7. The food intakes of sheep and the acids infused

\begin{tabular}{|c|c|c|c|}
\hline $\begin{array}{c}\text { Expt } \\
\text { no. }\end{array}$ & $\begin{array}{c}\text { Food intake } \\
(\mathbf{k g} \text { dry matter } / \mathrm{d})\end{array}$ & $\underset{\text { no. } \dagger}{\text { Animal }}$ & Precursors infused \\
\hline 1 & $\begin{array}{l}0.51 \text { hay and } \\
0.35 \text { flaked maize }\end{array}$ & 1,8 & 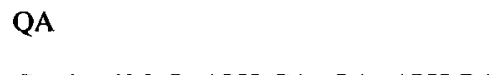 \\
\hline 2 & 0.74 dried grass & 2 & $\begin{array}{l}\text { Casein; } 3 \mathrm{MeO}, 4 \mathrm{OH}-\mathrm{CA} \text {; QA; } 4 \mathrm{OH}-\mathrm{BA} \\
\text { and 3,4,5OH-BA }\end{array}$ \\
\hline 3 & $\begin{array}{l}0.67 \text { hay and } \\
0.17 \text { sugar beet pulp }\end{array}$ & $\begin{array}{l}3,9 \\
4,10\end{array}$ & $\begin{array}{l}\text { 4OH-PA; arbutin; orcinol; 3OH-BA } \\
\text { QA; 2,5OH-BA; 3-PPA }\end{array}$ \\
\hline 4 & $\begin{array}{l}0.69 \text { hay and } \\
0.17 \text { sugar beet pulp }\end{array}$ & 3,9 & $\begin{array}{l}\text { 3MeO, } 4 \mathrm{OH}-\mathrm{BA} ; 3 \mathrm{MeO}, 4 \mathrm{OH}-\mathrm{CA} \\
\text { 4OH-CA; }\end{array}$ \\
\hline & & $\begin{array}{l}3 \\
4,10\end{array}$ & $\begin{array}{l}\text { Rutin } \\
\text { CA; 3,4,5OH-BA; PA; BA }\end{array}$ \\
\hline 5 & $\begin{array}{l}0.16 \text { hay and } \\
0.69 \text { sugar beet pulp }\end{array}$ & $5,6,7,11$ & $\begin{array}{l}\mathrm{CA} ; 2 \mathrm{OH}-\mathrm{CA} ; 3 \mathrm{OH}-\mathrm{CA} ; \\
4 \mathrm{OH}-\mathrm{CA} ; 3 \mathrm{MeO}, 4 \mathrm{OH}-\mathrm{CA} ; \mathrm{CHL}\end{array}$ \\
\hline 6 & $\begin{array}{l}0.17 \text { hay and } \\
0.69 \text { sugar beet pulp }\end{array}$ & $\begin{array}{l}5,6,7,11 \\
5 \\
6 \\
7,11 \\
6,7,11\end{array}$ & $\begin{array}{l}3,4 \mathrm{OH}-\mathrm{CA} ; \mathrm{QA} \\
3,4 \mathrm{OH}-\mathrm{BA} \\
\text { 2OH-BA } \\
\text { CHCA } \\
\text { BA }\end{array}$ \\
\hline 7 & 0.29 hay and 0.20 concentrate $*$ & 12 & - \\
\hline
\end{tabular}

QA, quinic acid; CHCA, cyclohexanecarboxylic acid; BA benzoic acid; PA, phenylacetic acid; 3-PPÁ, 3-phenylpropionic acid; CA, cinnamic acid; $\mathrm{OH}$, hydroxyl; $\mathrm{MeO}$, methyoxyl; $\mathrm{CHL}$, chlororgenic acid.

* Made up of $(\mathrm{g} / \mathrm{kg}): 550$ rolled oats, 175 decorticated groundnut meal, 175 bean meal and 100 cooked flaked maize.

$\dagger$ Animal nos. 1-7 inclusive had rumen cannulas and nos. 8-11 inclusive abomasal cannulas. Sheep no. 12 was not cannulated.

et al, 1978) and quinic acids (Balba \& Evans, 1977 a). This paper reports studies which show that quinic and cyclohexanecarboxylic acids are only partially metabolized by sheep to yield urinary benzoic acid. Studies have also been made of the influence of the rumen microflora on the metabolism of benzoic, phenylacetic, 3-phenylpropionic and cinnamic acids. Balba $\&$ Evans $(1977 b)$ have shown that on incubation of quinic, cyclohexanecarboxylic, benzoic or cinnamic acids with rumen fluid cultures the six-carbon ring can be completely degraded: long induction periods were required to establish this reaction. The results of the present studies do not suggest that aromatic ring fission is extensive in the ruminant animal. They also suggest that the principal urinary benzoic acid precursors are dietary constituents yielding 3-phenylpropionic acid on rumen fermentation.

\section{EXPER I MEN T A L}

Animals. Twelve 3- to 4-year-old wether sheep whose body-weights were between 55 and $72 \mathrm{~kg}$ were used in these experiments. Seven were Suffolk crosses and the remainder of the Cheviot breed. Sheep nos. 1-7 inclusive had rumen cannulas and sheep nos. 8-11 had abomasal cannulas. Sheep no. 12 had no cannula.

Experiments and rations. The rations used and acids infused in each of the seven experiments are given in Table 1. Before the start of each experiment the sheep were offered the ration for a period of at least 2 weeks. Food was given in two equal portions at 08.00 and 16.30 hours each day. Water was freely available at all times.

Collection of faeces and urine. The sheep were harnessed for faeces and urine collection as described by Wainman \& Paterson (1963). During the experiments the animals were kept in metabolism crates for periods of up to 10 weeks.

To prevent hydrolysis of aromatic acid glycine conjugates during the $24 \mathrm{~h}$ collection 
Table 2. Volumes of solutions infused and duration of experimental and control periods

\begin{tabular}{|c|c|c|c|c|c|c|c|}
\hline \multirow[b]{2}{*}{$\begin{array}{l}\text { Expt } \\
\text { no. }\end{array}$} & \multirow[b]{2}{*}{$\begin{array}{l}\text { Solution } \\
\text { infused }\end{array}$} & \multirow[b]{2}{*}{$\begin{array}{c}\text { Volume } \\
\text { infused } \\
(1 / d)\end{array}$} & \multicolumn{2}{|c|}{ Control periods } & \multicolumn{3}{|c|}{ Experimental periods } \\
\hline & & & $\begin{array}{l}\text { Duration } \\
\text { (d) }\end{array}$ & $\begin{array}{c}\text { Urine } \\
\text { assays } \\
\text { (day of } \\
\text { experiment) } \dagger\end{array}$ & $\begin{array}{l}\text { Duration } \\
\text { (d) }\end{array}$ & $\begin{array}{c}\text { Infusion } \\
\text { during } \\
\text { (day of } \\
\text { experiment) } \dagger\end{array}$ & $\begin{array}{c}\text { Urine } \\
\text { assays } \\
\text { (day of } \\
\text { experiment) } \dagger\end{array}$ \\
\hline 1$)$ & & 12 & 7 & 4-7 & 6 & $8-13$ & $10,11,12$ and 13 \\
\hline 2 & & 2 & 1 & 1 & 2 & 2 & 2 and 3 \\
\hline 3 & Saline & 2 & 4 & $1-4 \S$ & 3 & 5 & 5,6 and 7 \\
\hline 4 & & 12 & 4 & $1-48$ & 3 & 5 & 5,6 and 7 \\
\hline 5 & Water & 11 & 3 & 2 and 3 & 4 & $4-7$ & 6 and 7 \\
\hline 6$\}$ & Water & $\{1$ & 3 & 2 and 3 & 4 & $4-7$ & 6 and 7 \\
\hline $7 \ddagger$ & - & - & 7 & $4-7 \S$ & 10 & - & $8-17$ \\
\hline
\end{tabular}

* The saline solution contained $(\mathrm{g} / \mathrm{l}) 6 \mathrm{NaCl}, 0.4 \mathrm{KCl}, 0.2 \mathrm{MgCl}_{2}, 0.2 \mathrm{CaCl}_{2}$ and $0.45 \mathrm{NaH}_{2} \mathrm{PO}_{4} .2 \mathrm{H}_{2} \mathrm{O}$.

+ Numbered sequentially from the start of the control infusion period to the end of the experimental period.

$\ddagger$ No infusions were made in Expt 7 . Urinary outputs were determined during a control feeding period and subsequently in a $10 \mathrm{~d}$ fasting period.

$\S$ In these periods urine assays other than creatinine were made using a composite sample prepared from equal proportions of each of the four urines.

periods the $\mathrm{pH}$ of the urine was not allowed to exceed 4 . Dilute hydrochloric acid $(0 \cdot 1 \mathrm{M})$ was added to the urine reservoirs at 09.00 and 16.30 hours in amounts predetermined to yield a final $\mathrm{pH}$ of $4 \cdot 0$. The daily output of urine was weighed, its specific gravity recorded and samples not analysed inmediately stored in polyethylene bottles at $-20^{\circ}$.

Experimental plans. The duration of control and experimental periods varied in each experiment. In Expts 1-6 saline (Table 2) or water infusions were given throughout the experiment as a continuous drip through the animal's cannula: during experimental periods potential benzoic acid precursors were included in these infusions. The rates of infusion were controlled by peristaltic pumps (Varioperpex; LKB, Surrey, England or Minipuls 2; Gilson, France). The duration of the periods, the solutions infused and their rates of infusion together with the days on which samples of urine were taken for aromatic acid analysis are given in Table 2. Urinary creatinine output was determined each day.

The acids infused were the purest available and were infused as received. British Drug Houses Ltd, Poole, Dorset supplied benzoic, phenylacetic, 3-phenylpropionic and cinnamic acids; Fluorochem Ltd (Fluka), Glossop, Derbyshire supplied cyclohexanecarboxylic acid and Koch-Light Ltd, Colnbrook, Bucks. supplied D(-)-quinic acid.

The amounts of material infused were determined each day by weighing. In Expts $1-4$ inclusive the quantity infused was taken as the product of the weight of solution infused and the concentration of the solution. To check the stability of the infused solutions over $6 \mathrm{~d}$ periods in Expts 5 and 6 (the infusions were prepared on day 2) samples were assayed on the day of preparation and on each of the four infusion days. Autotitration with alkali ( 0.1 M-sodium hydroxide in a Radiometer ABU 12 autotitrator, Copenhagen, Denmark) was used for quinic (end point $\mathrm{pH} 7.80$ ) and cyclohexanecarboxylic (end point $\mathrm{pH} 8.40$ ) acids. With the other acid infusions samples were diluted between 200 and 500 times and their u.v. absorbance recorded between 350 and $220 \mathrm{~nm}$ using an SP800 recording spectrophotometer (Pye-Unicam Ltd, York Street, Cambridge). The absorption maxima and molecular extinctions ( $\epsilon$ in parentheses) used to calculate infusion concentrations were: sodium benzoate, $224 \mathrm{~nm}(8170)$ and sodium cinnamate, $269 \mathrm{~nm}$ (19420). Infusion solutions were prepared by dissolving the acids in water to which exactly the amount of $\mathrm{NaOH}$ required 
to neutralize the acid present (if the $\mathrm{Na}$ salt was to be prepared) was added. No change in the absorbance of any infusion samples was found between preparation and the end of the experimental period. The amounts of acids infused are recorded in Tables 4 and 5 .

\section{Urine analyses}

Creatinine. The daily output of creatinine was determined in all experiments to assess the efficiency of urine collection and if necessary correct for losses.

Expts 1 and 2. Creatinine was determined by G-10 Sephadex (Pharmacia Ltd), Uppsalla, Sweden) column chromatography as described previously (Martin, 1973).

Expts 3 to 7. The McEvoy-Bowe (1966) method in which urine samples are applied to small DEAE Sephadex columns (Pharmacia Ltd, Sweden) and the u.v. absorbance of the eluate determined was modified slightly to enable its use with ruminant urine containing large amounts of u.v. absorbing anions. A-25 gel was used in place of the A-50 grade and the length of the $10 \mathrm{~mm}$ diameter column increased to $100 \mathrm{~mm}$. The absorbance of the eluate was recorded between 290 and $220 \mathrm{~nm}$ with an SP800 spectrophotometer. Creatinine absorbs no radiation at $270 \mathrm{~nm}$ and any such absorbance was deducted from that found at the $\lambda_{\max }$ of $233 \mathrm{~nm}$. In most samples, fractions eluting just before creatinine (i.e. $<8 \mathrm{ml}$ ) and just after creatinine (i.e. $>12 \mathrm{ml}$ elution volume) showed a small and almost constant absorbance between 270 and $230 \mathrm{~nm}$.

Aromatic acid glycine conjugates. In some experiments unhydrolysed urine was assayed on sampling for these compounds.

Expt 2. Approximately $0.01 \%$ of the daily urine output in $1 \mathrm{ml} 0.1 \mathrm{M}$-phosphate buffer, $\mathrm{pH} 7 \cdot 0$, was applied to the G-10 Sephadex columns ( $400 \mathrm{~mm}$ long, $10 \mathrm{~mm}$ internal diameter) used in urine creatinine assay. The column was eluted at $0.4 \mathrm{ml} / \mathrm{min}$ (Varioperpex pump, LK B Instruments, Sweden) with the same buffer solution. Creatinine eluted between 18 and $26 \mathrm{ml}$ followed by co-elution of hippuric, phenylacetic and phenaceturic acids between 26 and $42 \mathrm{ml}$ and then by benzoic acid between 41 and $58 \mathrm{ml}$. The absorbance of the eluate was monitored continuously at $233 \mathrm{~nm}$ as it passed through a $2 \mathrm{~mm}$ path-length flow cell in an SP800 spectrophotometer equipped with an SP150 scale expansion accessory and an output to an SP21 stripchart recorder (Pye-Unicam Ltd, Cambridge) operated at $5 \mathrm{~mm} / \mathrm{min}$. Phenylacetic and phenaceturic acids do not absorb light at $233 \mathrm{~nm}$. The areas under hippuric acid and creatinine peaks were proportional to the amount applied to the columns: replication of duplicate urinary hippuric acid assay was better than $1 \%$. No free benzoic acid was found in any samples.

Expts 3, 4 and 7. Approximately $0 \cdot 2 \%$ of the daily urine output was used to determine the hippuric and phenaceturic acid content of the samples by gas-liquid chromatography of their methyl esters (Martin, 1973). Coefficients of variation of replicate hippuric and phenaceturic acid assays averaged 3.5 and 5.7 respectively.

Titratable acids of diethylether- and toluene-soluble extracts of hydrolysed urine. Between 0.5 and $3.0 \%$ of the daily urine output was hydrolysed by heating in a stoppered tube with 0.125 vol. $10 \mathrm{M}$-potassium hydroxide at $95^{\circ}$ for $16 \mathrm{~h}$. The acids present in ether or toluene extracts were then determined as previously described (Martin, 1973). All results were expressed in terms of benzoic acid equivalent (BAE). Diethyl ether-soluble acids were determined in Expts 1-4 inclusive and Expt 7 and toluene-soluble acids in Expts 1 and 3-7 inclusive. Replication of duplicate extracts was within $2 \%$ for both solvent extracts.

Gas-liquid chromatography of the toluene-soluble acids in hydrolysed urine. These assays were made in Expts 1 and 3-6 inclusive. After determination of the titratable acids present in the sample another portion was evaporated under nitrogen to give a concentration of $1 \mathrm{mg} \mathrm{BAE} / \mathrm{ml}$. An amount of internal standard in toluene was then added to give a weight ratio for BAE: internal standard of 1 . An excess of diazomethane in diethyl ether (prepared 
from 'Diazald', Aldrich Chemical Co., Gillingham, Dorset) was added and after 1 min between 1 and $10 \mu \mathrm{g}$ methylated BAE was injected onto the chromatography column.

Expts $I$ and 7. Glass columns (1524 mm long, $4 \mathrm{~mm}$ i.d.) containing 50 g neopentylglycol succinate/kg 80-100 mesh Universal B Support (Phase Separations Ltd, Clwyd) were used in a Pye 104 dual-flame-ionization gas chromatograph whose output was recorded on a $1 \mathrm{mV}$ recorder (Honeywell Elektronic 194, Honeywell Ltd., Newhouse, Lanarkshire). Chromatograph operating conditions have been described previously (Martin, 1973).

Expts 3 and 4. Small amounts of aromatic acids, particularly 3-phenylpropionic and cinnamic acids, could not be quantitatively assayed in Expts 1 and 7. To increase the sensitivity of the assay the column oven temperature was maintained at $150^{\circ}$ (an initial temperature of $115^{\circ}$ was used in Expts 1 and 7) and larger amounts of BAE injected (3-6 $\left.\mu \mathrm{g}\right)$. The amounts of aromatic acids present relative to the tridecanoic acid internal standard were determined by values for the peak height ratio. To keep the benzoic acid peak on scale the amplifier attenuation was increased from $10 \times 10^{2}$ to $50 \times 10^{2}$ whilst that peak eluted. Relative retentions of phenols and acids present in the samples to tridecanoic acid were: cyclohexanecarboxylic acid $0 \cdot 12$, benzoic acid $0 \cdot 26$, phenylacetic acid $0 \cdot 44,3$-phenylpropionic acid 0.64 , phenol 0.65 , p-cresol 0.92 , p-ethylphenol $1 \cdot 36$, cinnamic acid 1.46 .

Expts 5 and 6. A Hewlett-Packard 5711A dual-flame-ionization gas chromatograph, 3373B integrator and $1 \mathrm{mV}$ 7123B recorder (Hewlett-Packard, Winnersh, Wokingham, Berkshire) was used in these experiments. Glass columns (1830 mm long, $4 \mathrm{~mm}$ i.d.) packed as already described were used with argon as carrier gas at an inlet pressure of $4 \cdot 1$ bar which gave a flow rate of $60 \mathrm{ml} / \mathrm{min}$ : hydrogen and air flow-rates were 60 and $240 \mathrm{ml} / \mathrm{min}$ respectively. An electrometer attenuation of 100 and integrator attenuation of 10 gave an output of $5 \times 10^{-9} \mathrm{~A}$ to the recorder for a full scale deflection. The detector oven was maintained at $300^{\circ}$; the analyser oven was kept at $100^{\circ}$ for 4 min and then increased at $8 \% \mathrm{~min}$ to $150^{\circ}$ and held there for $16 \mathrm{~min}$. These conditions allowed better resolution of cyclohexanecarboxylic acid from the solvent front. Lauric acid (as methyl laurate 'specially pure', British Drug Houses, Poole, Dorset) was used as the internal standard and the relative retentions to the standard of the acids and phenols found in the toluene extracts were: cyclohexanecarboxylic acid $0 \cdot 37$, benzoic acid $0 \cdot 60$, phenylacetic acid $0 \cdot 75,2$-hydroxybenzoic acid $0 \cdot 76,3$-phenylpropionic acid $0 \cdot 88$, $p$-cresol $1 \cdot 00$, $p$-ethyl phenol 1·23, cinnamic acid 1.32.

Isolation of cinnamic acid by preparative gas-liquid chromatography. To confirm the identity of cinnamic acid, methyl cinnamate was isolated from one urine sample in Expt 3 and from five in Expt 4. A modified manual preparative kit (Christie, 1974) was used with a Pye 104 chromatograph fitted with a glass preparative column (2134 $\mathrm{mm}$ long, $9 \mathrm{~mm}$ i.d.) packed with $50 \mathrm{~g} \mathrm{SE30/kg} \mathrm{Chromosorb} \mathrm{W/HP,} \mathrm{80/100} \mathrm{mesh} \mathrm{(Phase} \mathrm{Separations} \mathrm{Ltd,}$ Clwyd). Cinnamic acid $(0.25 \mathrm{mg}$ in $100 \mu \mathrm{l}$ toluene) was methylated for $1 \mathrm{~min}$ with $1 \mathrm{ml}$ diazomethane in diethyl ether (from 'Diazald'). Excess reagent was removed in a fume cupboard with a stream of $\mathrm{N}_{2}$ and the solution concentrated to $100 \mu$ l. The sample $(50 \mu l)$ was injected at a column oven temperature of $200^{\circ}$ with a $99: 1$ splitter directing $1 \%$ of the column effluent to the flame-ionization detector. The retention time of methyl cinnamate was $10.5 \mathrm{~min}$.

Urine samples ( $1 \%$ of the daily output) were hydrolysed as already described and the toluene extracts concentrated to 0.5 and $0.1 \mathrm{ml}$ portions methylated for 1 min with $2 \mathrm{ml}$ diazomethane in diethyl ether. The diethyl ether and excess diazomethane was removed under $\mathrm{N}_{2}$ and $30-50 \mu$ of the methylated extract injected onto the column. The peak eluting at $10.5 \mathrm{~min}$ was collected in a $50 \mathrm{~mm}$ glass column of 60 mesh glass beads moistened with ethanol. The methyl cinnamate was eluted with $5 \mathrm{ml}$ ethanol and the u.v. absorbance of the eluate determined in $10 \mathrm{~mm}$ path length cells in an SP800 recording spectrophotometer from 350 to $210 \mathrm{~nm}$. 


\section{Aromatic acids in rumen fluid}

Expt 5. Rumen fluid samples $(100 \mathrm{ml})$ were taken from sheep nos. 5 and 6 at 15,1 and $4 \mathrm{~h}$ after the previous feed on the third day of five control periods and on the final day when cinnamic acid was infused.

Expt 6 . The samples noted previously were taken and three additional ones at 2,6 and $9 \mathrm{~h}$ after the morning feed. Sheep nos. 5 and 6 were sampled on the last day of all control and experimental periods and sheep no. 7 on cyclohexanecarboxylic acid infusion and during the preceding control period.

Rumen fluid was strained through three layers of muslin and then deproteinized. To $50 \mathrm{ml}$ of the filtrate were added $50 \mathrm{ml}$ sodium tungstate dihydrate $(100 \mathrm{~g} / 1)$ and $60 \mathrm{ml} 0.335 \mathrm{M}$ suphuric acid. The solutions were mixed, centrifuged $(22000 \mathrm{~g})$ for $10 \mathrm{~min}$ at $5^{\circ}$ and the supernatant fraction decanted. Portions $(40 \mathrm{ml})$ were extracted three times with redistilled toluene. The first solvent extract contained $1 \mathrm{mg}$ methyl laurate as internal standard. The solvent was purified by passage through a $20 \times 170 \mathrm{~mm}$ column of activated alumina (neutral, Brockman activity 1) and then redistilled using a Vigreux fractionating column, the fraction distilling at $110-111^{\circ}$ being collected.

The combined organic extracts were concentrated in vacuo (Buchi Rotavapor $\mathrm{R}$, Orme Scientific, Manchester) to $2 \mathrm{ml}$. The concentrated extract $(0.8 \mathrm{ml})$ was methylated with $0.4 \mathrm{ml}$ diazomethane in diethyl ether for $1 \mathrm{~min}$. Aromatic acids were assayed as described previously for Expts 5 and 6 . The volume injected onto the chromatography column was $4 \mu \mathrm{l}$.

\section{Quinic acid}

Extraction and assay. Quinic acid was isolated by anion-exchange chromatography and assayed by reaction of its periodic acid oxidation product, citric dialdehyde, with 2thiobarbituric acid to yield a pink chromogen with a $\lambda_{\max }$ of $549 \mathrm{~nm}$. The method used for colorimetric assay was a modification of that of Mesnard \& DeVaux (1964).

Samples were passed through a $100 \times 10 \mathrm{~mm}$ column of $100 / 200$ mesh Zeocarb $225 \mathrm{H}^{+}$ to remove cations and then through a $300 \times 10 \mathrm{~mm} \mathrm{100/200}$ mesh Deacidite FF, formate form, anion-exchange column. The samples $(25 \mathrm{ml}$ urine or centrifuged ( $2100 \mathrm{~g}$ for $10 \mathrm{~min})$ rumen fluid) were pumped onto the columns at $2 \mathrm{ml} / \mathrm{min}$ (Varioperpex peristaltic pump) and washed with water until the elute was free of carbohydrate (phenol-sulphuric acid test). Quinic acid was eluted from the deacidite column with $2 \mathrm{M}$-formic acid. Fractions were collected $(10.5 \mathrm{ml} ; 180$ drops using an Ultrorac 7000 fraction collector; LKB Instruments, Sweden) and fractions nos. 2-6 inclusive were combined and diluted to 100 or $250 \mathrm{ml}$ with water.

A portion of the diluted eluate (1-3 ml containing up to $20 \mu \mathrm{g}$ quinic acid) was put in a glass stoppered test-tube and $1 \mathrm{ml} 0.025 \mathrm{M}$-periodic acid in $0.063 \mathrm{M}-\mathrm{H}_{2} \mathrm{SO}_{4}$ was added, mixed and left for $10 \mathrm{~min}$. Excess periodate was removed with $2 \mathrm{ml}$ sodium arsenite in $0.5 \mathrm{M}-\mathrm{HCl}(20 \mathrm{~g} / 1)$. Freshly-prepared recrystallized 2-thiobarbituric acid $(6 \mathrm{~g} / 1)$ in $0.5 \mathrm{M}-$ sodium sulphate at $\mathrm{pH} 5.0$ was added $(2 \mathrm{ml})$ and the stoppered tube heated on a boiling water-bath for $30 \mathrm{~min}$. The tubes were cooled in a water-bath at $40^{\circ}$ and $4 \mathrm{ml}$ cyclohexanone added and the contents shaken for $20 \mathrm{~s}$. The extraction was repeated once with $4 \mathrm{ml}$ cyclohexanone and the combined organic phases centrifuged $\left(1910 \mathrm{~g}, 10 \mathrm{~min}, 15^{\circ}\right)$ to give a clear pink solution. Standard assays were made with each batch of assays to determine the molecular extinction to be used in calculating quinic acid concentration. In different batches of assays $\epsilon$ varied between 21000 and 38000 . However, within any batch of assays Beers Law was obeyed closely. The instability of the 2-thio-barbituric acid sulphate reagent was thought to be the cause of the variation in $\epsilon$. Absorbance was determined in an SP800 recording spectrophotometer between 600 and $400 \mathrm{~nm}$. 
When between 0.1 and $5.0 \mathrm{mg}$ quinic acid was added to urine or rumen fluid samples recoveries of quinic acid were $101.6 \pm 4.1 \%$ (mean and standard deviation; eight experiments). The formic acid in the eluate yielded a peak at $450 \mathrm{~nm}$ which did not interfere with the quinic acid chromogen.

In vitro metabolism of quinic acid. The apparatus described by Czerkawski \& Breckenridge (1969) was used to study the rate of quinic acid metabolism in the rumen. Fermentation vessels contained $200 \mathrm{ml}$ rumen fluid from a sheep fed on dried-grass cubes, $200 \mathrm{ml}$ artificial saliva and $100 \mathrm{ml}$ water containing $200 \mathrm{mg}$ ammonium carbonate and other additives as required. Gas samples were taken 2 and $4 \mathrm{~h}$ after the start and total gas production noted at $30 \mathrm{~min}$ intervals throughout the $7 \mathrm{~h}$ experiments. Fluid samples for analysis were withdrawn after $5 \mathrm{~min}, 2,4,6$ and $7 \mathrm{~h}$.

\section{RESULTS}

\section{Outputs of urinary acids in control periods}

The mean weights of the sheep and their mean daily creatinine and aromatic acid outputs in the control periods of each experiment are given in Table 3. In Expts 3 and 4 benzoic and phenylacetic acid outputs were determined both as glycine conjugates in unhydrolysed urine or as free acids in alkali hydrolysed urine: mean results are given in Table 3 . The present study suggests that urinary 3-phenylpropionic acid and cinnamic acid arise from a common precursor and for this reason the individual outputs of these two acids are combined in all Tables. 3-Phenylpropionic and cinnamic acids were only determined in Expts 3-6.

The titratable acids in diethylether extracts of hydrolysed urine, in addition to aromatic acids, contain phenolic and some aliphatic acids. Usually, the only toluene-soluble acids are the non-phenolic aromatic acids (Martin, 1973) but 2-hydroxybenzoic acid was found to be toluene-soluble; 2-hydroxyphenylacetic, 3-phenylpropionic or cinnamic acids were not extracted by toluene. Benzoic, phenylacetic, 3-phenylpropionic and cinnamic acids comprised $96 \pm 8 \%$ and $56 \pm 7 \%$ respectively of the toluene- and diethylether-soluble titratable acids (control period means and standard deviations; $n 62$ and 38 respectively).

Within experiments significant differences ( $t$ test; $P<0.05$ ) were noted between sheep in their urinary output of aromatic acids. These differences were too great to be due to errors in urine collection; the urinary creatinine outputs (Table 3) did not suggest systematic errors of this type. In all experiments in which 3-phenylpropionic and cinnamic acids were determined there were significant $(P<0.05)$ differences between sheep in the output of these acids.

\section{Calculations of increments in urinary aromatic acid output}

The daily urinary creatinine output of each sheep in each control and experimental period was determined and from this the control output of aromatic acids/g creatinine was calculated. The basal aromatic acid output in experimental periods was then calculated as the product of the urinary creatinine output in that period and the control output of aromatic acids/g creatinine.

In Expts 1, 5 and 6 infusions lasted for several days (Table 2) and a steady state was achieved. The increment over the calculated basal output was determined for each sample analysed (Table 2) and the mean calculated. In Expts 2, 3 and 4 infusions were of $24 \mathrm{~h}$ duration and the total increment over the calculated basal output determined on the day of infusion and $1 \mathrm{~d}$ (Expt 2) or $2 \mathrm{~d}$ (Expts 3 and 4) following. 
A. K. Martin

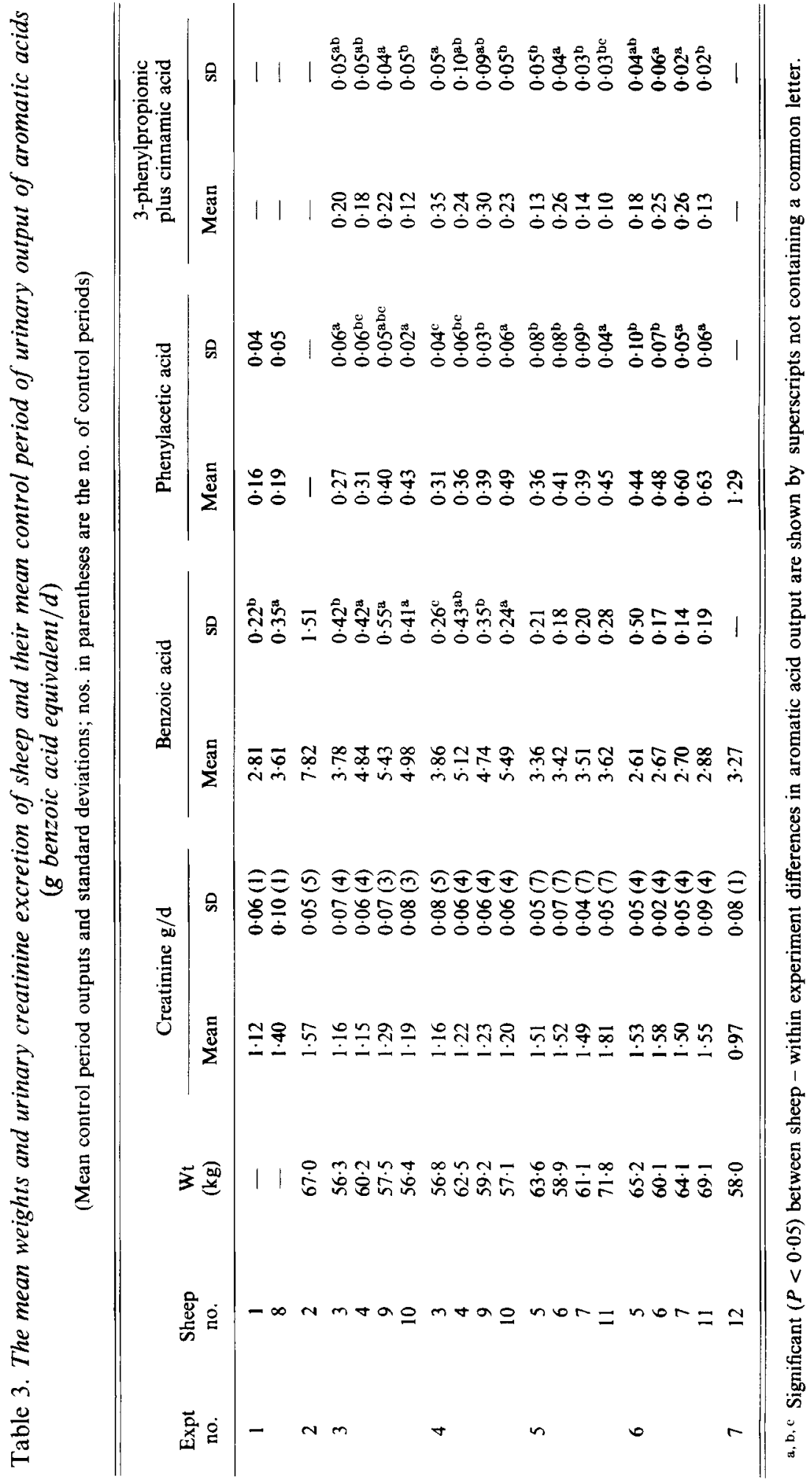




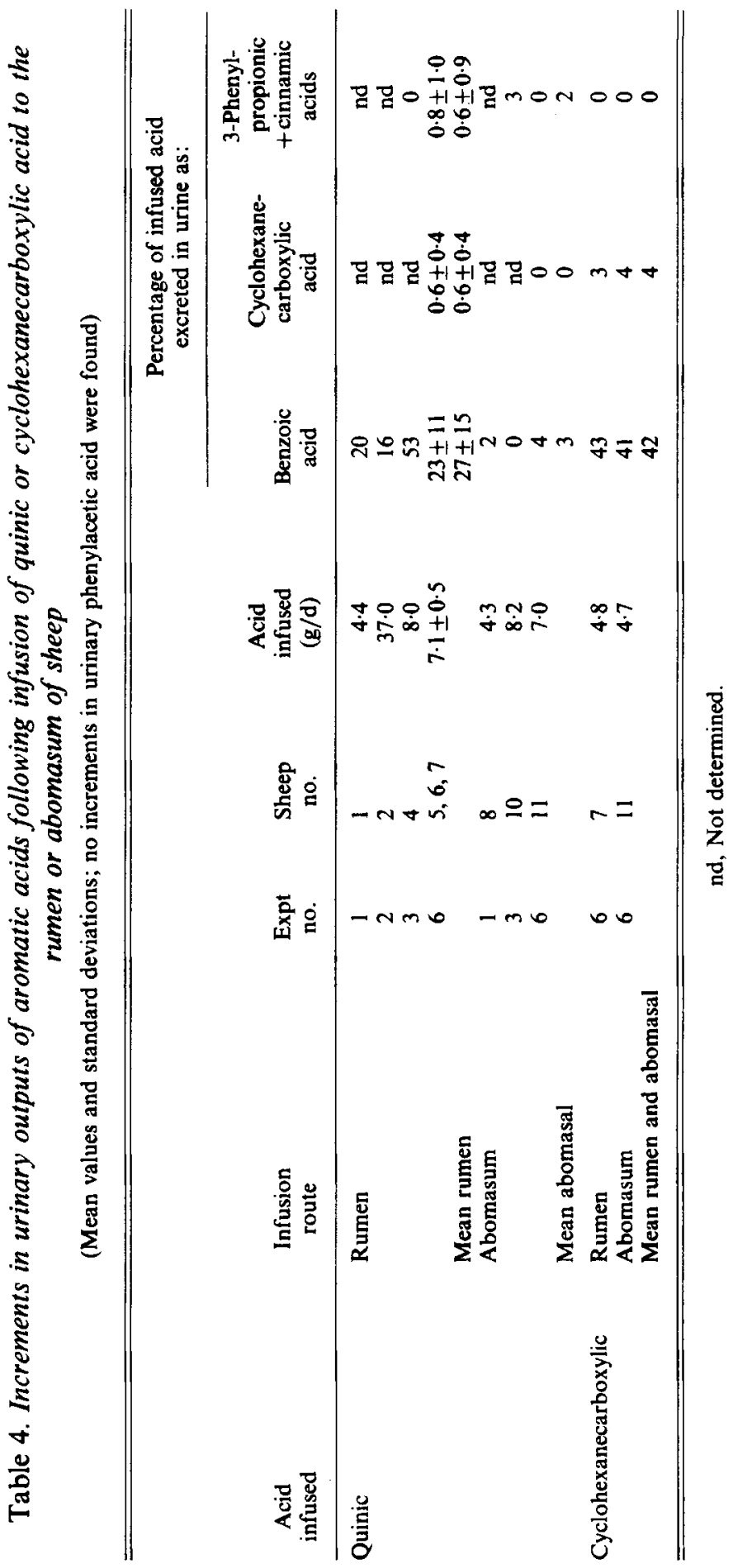




\section{Quinic and cyclohexanecarboxylic acid infusion}

The increments found in urinary aromatic acids after rumen or abomasal infusion of these acids are given in Table 4. After rumen quinic acid infusion variable proportions of the infused acid appeared in the urine as incremental benzoic acid: the three sheep in Expt 6 excreted 16,18 and $36 \%$ of the dose as urinary benzoic acid and the greatest urinary benzoic acid increment was $53 \%$ of the infused acid. Small amounts of rumen-infused quinic acid appeared in the urine as cyclohexanecarboxylic acid $(<1 \%)$. On abomasal infusion of quinic acid no significant urinary increments in aromatic acid output were found.

Aromatization of cyclohexanecarboxylic acid was similar after both rumen or abomasal infusion: almost half the acid was recovered as benzoic acid and small amounts (3-4\%) excreted unchanged.

In Expt 1 unhydrolysed urines were assayed for quinic acid (see p. 144). The method was capable of detecting outputs of $5 \mathrm{mg} / \mathrm{d}$ but no quinic acid could be found after either rumen or abomasal infusion of the acid.

The rate of metabolism of quinic acid by rumen micro-organisms was studied in experiments with an artificial rumen apparatus (experimental section). When relatively large quantities of quinic acid ( $1 \mathrm{~g}$ neutralized with sodium hydroxide) were added to the system no change in quinic acid concentration was noted over the $6 \mathrm{~h}$ period of the experiment. However, when smaller amounts of neutralized quinic acid $(0 \cdot 1 \mathrm{~g})$ were incubated with rumen micro-organisms in the presence (vessel no. 2) or absence (vessel no. 3) of $1.5 \mathrm{~g}$ sucrose, metabolism of quinic acid was more pronounced. After $2 \mathrm{~h}$ of incubation $13 \%$ of the quinic acid in vessel no. 2 and $48 \%$ of that in vessel no. 3 remained; after $4 \mathrm{~h}$ incubation no quinic acid remained in vessel no. 2 and $28 \%$ of the initial amount in vessel no. 3 ; after 6 or $7 \mathrm{~h}$ no quinic acid could be detected in any vessel. Quinic acid inhibited the rates of gas production during fermentation. The production of gas in vessel no. 2 was expressed as a percentage of that in a control vessel to which $1.5 \mathrm{~g}$ sucrose but no quinic acid had been added: after 2 and $4 \mathrm{~h}$ incubation methane production was 52 and $42 \%$; hydrogen production 86 and $60 \%$ and carbon dioxide production 83 and $50 \%$ respectively of the control amounts.

\section{Infusion of aromatic acids}

Urinary recoveries obtained in fifteen determinations when benzoic, phenylacetic, 3-phenylpropionic and cinnamic acids were infused are summarized in Table 5.

\section{Isolation of cinnamic acid from hydrolysed urine}

The acid was isolated as its methyl ester (see p. 143) and its identity confirmed by comparison of its u.v. absorption spectrum in ethanolic solution with that of authentic methyl cinnamate. Identical spectra were obtained from the urinary compound isolated by preparative gas-liquid chromatography and from methyl cinnamate: both showed a principal $\lambda_{\max }$ at $275 \mathrm{~nm}, \lambda_{\min }$ at $231 \mathrm{~nm}$ and subsidiary $\lambda_{\max }$ at 222 and $216 \mathrm{~nm}$.

\section{Cyclohexanecarboxylic and aromatic acids in rumen fluid}

The mean concentrations of cyclohexanecarboxylic and non-phenolic aromatic acids in rumen fluid samples taken during control periods of Expts 5 and 6 and when quinic, cyclohexanecarboxylic or non-phenolic aromatic acids were infused are shown in Fig. 1.

During control periods in Expt 5 the concentration of cyclohexanecarboxylic acid was greatest $1 \mathrm{~h}$ after feeding ( $\sim 7 \mathrm{mg} \mathrm{BAE} / 1$ rumen fluid); in Expt 6 many control period rumen fluid samples contained no detectable cyclohexanecarboxylic acid. When 4.3-4.8 g BAE of quinic acid/d were infused increments in rumen fluid concentrations of cyclohexanecarbo- 


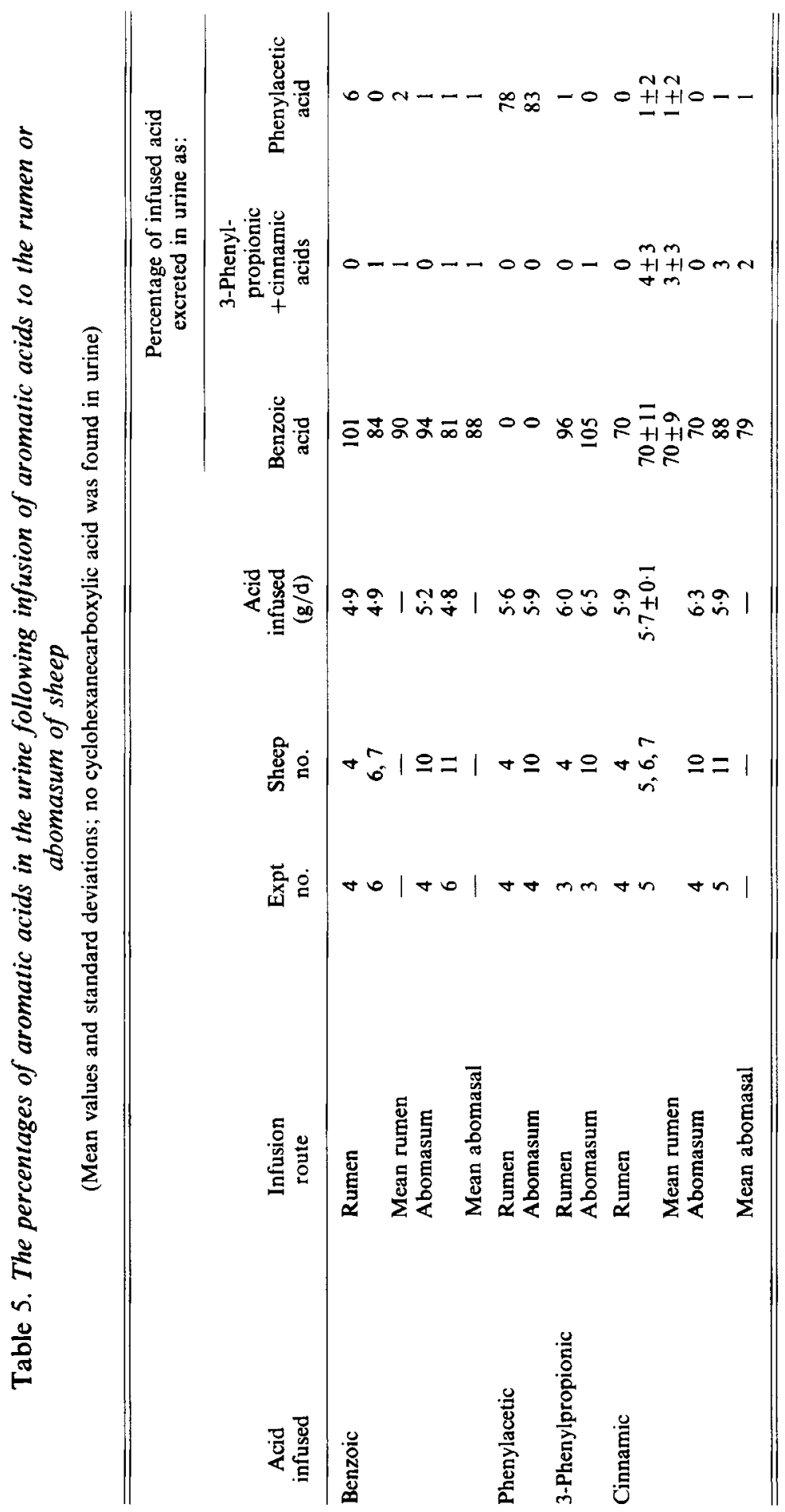



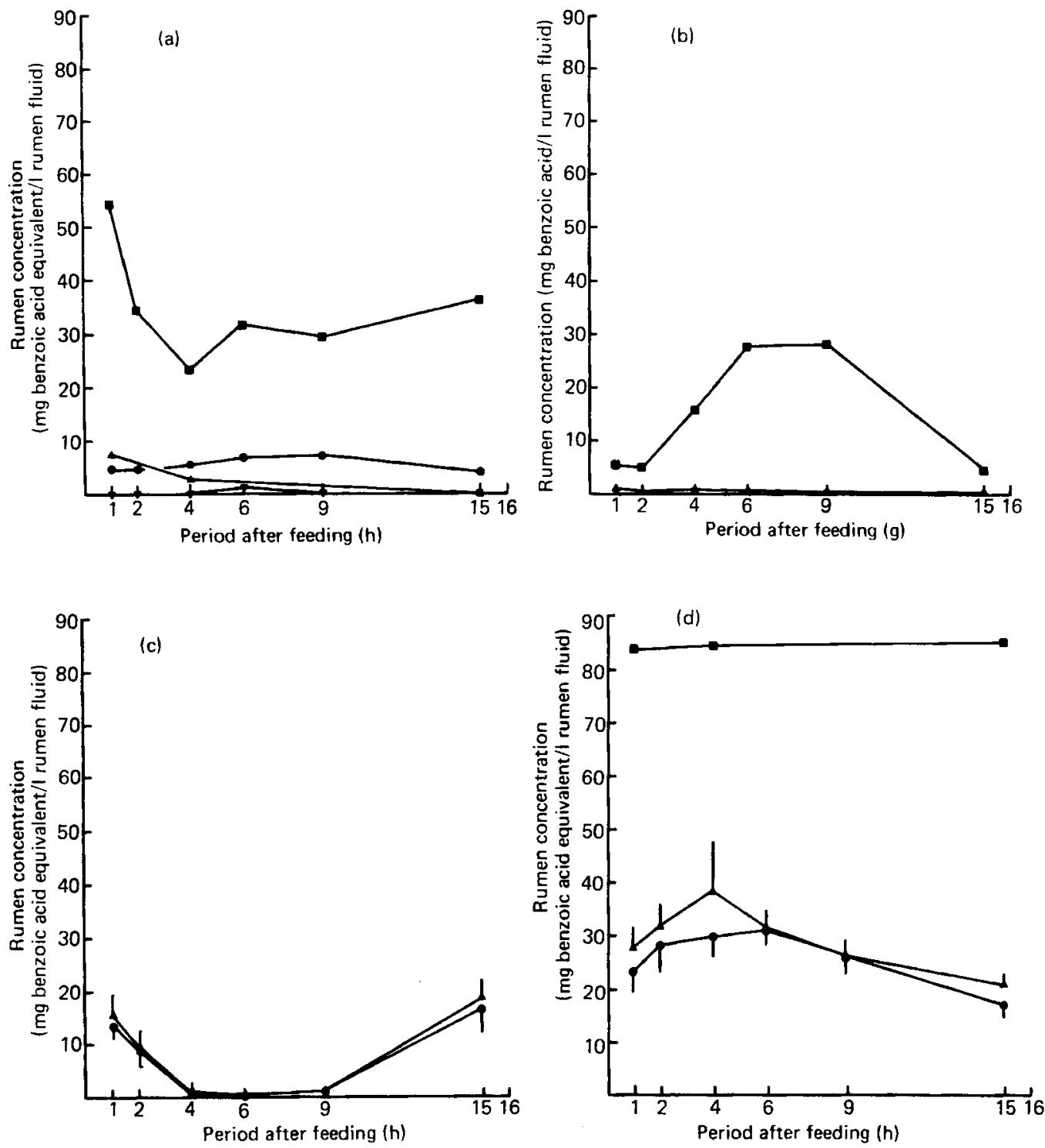

Fig. 1. Expts 5 and 6. The mean concentrations of cyclohexanecarboxylic and aromatic acids in rumen fluid of sheep in relation to time of feeding (a) cyclohexanecarboxylic acid: $(\boldsymbol{\Delta})$, control periods, Expt $5(n 5) ;(\nabla)$ control periods, Expt $6(n 9) ;(\Theta)$, quinic acid infusion $(n 2) ;(\square)$, cyclohexanecarboxylic acid infusion, $(n 1)$ (b) Benzoic acid: (A), control periods, Expts $5(n 5)$ and $6(n 9)$, and all other acids (see Table 1) except benzoic acid ( $n$ 18); ( $(\mathbf{)})$, benzoic acid infusion. (c) Phenylacetic acid: (A), control periods in Expts $5(n)$ and $6(n 9)$; (O), infusion of all acids in Table $1(n$ 19). (d) 3-Phenylpropionic acid: ( $\Delta)$, control periods, Expts $5(n 5)$ and $6(n 9)$; $(O)$, quinic $(n 2)$, cyclohexanecarboxylic $(n 1)$ and benzoic $(n 1)$ acid infusion; $(\square)$, cinnamic acid $(n 2)$ infusion. Points are mean values and one standard deviation is represented by vertical bars. In Expt 5 samples were only taken at 1,4 and $15 \mathrm{~h}$ after feeding. 
xylic acid were found and when $4.6 \mathrm{~g}$ BAE of cyclohexanecarboxylic acid itself/d were infused its concentration in rumen fluid varied between 23 and $54 \mathrm{mg}$ BAE/1 (Fig. 1 a).

The maximum benzoic acid concentration in rumen fluid in any period or sampling time other than when benzoic acid itself was infused was $2.1 \mathrm{mg} / \mathrm{l}$. On benzoic acid infusion its concentration in rumen fluid varied with sampling time from 2.4 to $28.4 \mathrm{mg} / 1$ (Fig. 1 b).

Phenylacetic acid concentration was unaffected by any of the acids (Table 1) infused in Expts 5 and 6. Its concentration was smallest between 4 and $9 \mathrm{~h}$ after feeding (Fig. $1 \mathrm{c}$ ).

3-Phenylpropionic acid was the most abundant aromatic acid in rumen fluid with its concentration increasing to a maximum between 4 and $6 \mathrm{~h}$ after feeding (Fig. $1 \mathrm{~d}$ ).

\section{DISCUSSION}

\section{Metabolism of quinic and cyclohexanecarboxylic acids}

Quinic acid was partially recovered in urine as benzoic acid $(27 \pm 15 \%)$ after rumen infusion but no such increment was found after abomasal infusion (Table 4). Cyclohexanecarboxylic acid is a microbial metabolite of alicyclic acids (Balba \& Evans, 1977a; Brewster et al. 1978) and has been found in the urine of cattle (Suemitsu et al. 1971). In the present experiments this acid was found in urine only after rumen or abomasal infusion of cyclohexanecarboxylic acid itself $(4 \%$ of the dose) or when quinic acid was infused into the rumen $(0.6 \pm 0.4 \%$ of the dose). However, cyclohexanecarboxylic acid was a normal constituent of control period rumen fluid samples; especially in those of Expt 5 (Fig. 1a). Liver enzymes may dehydrogenate absorbed cyclohexanecarboxylic acid to yield benzoic acid (Babior \& Bloch, 1966) and smaller amounts of 3,4,5,6-tetrahydroxybenzoate (Brewster et al. 1977). Thus, in the present experiments it was expected that both rumen and abomasal infusion of cyclohexanecarboxylic acid would yield urinary benzoic acid; this was so and benzoic acid equivalent to $\sim 40 \%$ of the dose was excreted in urine.

Although the detailed metabolic rates of quinic and cyclohexanecarboxylic acids in the animal body are not yet known, a number of reasons for the incomplete aromatization of these acids can be suggested. The variation in quinic acid aromatization in the present experiment is typical of those found in studies with other species (Scheline, 1978). The present studies have shown that moderate amounts of quinic acid $(0.5 \mathrm{~g} / 1$ rumen fluid) were completely metabolized by rumen micro-organisms (Expt 1) and that some cyclohexanecarboxylic acid accumulated in rumen fluid on quinic acid infusion (Expt 6). No quinic acid was found in urine samples (Expt 1) although this acid has been found to be a normal constituent of human urine (Halpern, 1960): it would not be expected in urine after rumen fermentation but its absence from urine after abomasal quinic acid infusion is less easy to explain. As cyclohexanecarboxylic acid was only partially aromatized in these experiments incomplete aromatization of quinic acid was expected. The cyclohexanecarboxylic acid not recovered in these experiments may have suffered at least two alternative metabolic fates. First, it may be excreted in the bile: Brewster et al. (1977) found that rats excreted increasing proportions of cyclohexanecarboxylic acid in the bile (as its glucuronide) as the dose of acid given was increased; the fate of the biliarily-excreted acid was not determined but faecal excretion is a possibility; faeces samples were not analysed in the present studies. Secondly, cyclohexanecarboxylic acid can be dissimilated to $\mathrm{CO}_{2}$ and methane in anaerobic microbial culture (Keith et al. 1978); the significance of such reactions in vivo is not known. Orpin (1975) has reported that rumen micro-organisms can use quinic acid in catabolic and anabolic reactions. There may be other reasons for the incomplete aromatization of quinic acid as cyclohexanecarboxylic acid may not be the only microbial metabolite: Brewster $e t$ al. (1978) showed that microbial metabolism of a related alicyclic acid, shikimic acid, in the rat intestine resulted in the faecal excretion of approximately one-third of an oral dose of the acid as 3,4-dihydroxycyclohexanecarboxylic acid. Similar reactions of quinic acid may be a further reason for the limited aromatization found in the present experiments. 
Traces of benzoic acid were found in some rumen fluid samples in the present experiments (Fig. 1b). Indahl \& Scheline (1973) stated that rat caecal micro-organisms were able to produce benzoic acid when incubated with quinic acid but no quantitative information was given. Rumen quinic acid infusion did not increase rumen fluid benzoic acid concentration (Expt 6) but as the small benzoic acid concentrations found in rumen fluid were at the limit of detection of the method as used in these experiments small changes would be difficult to detect. Possibly the traces of benzoic acid found in rumen fluid do arise from a minor pathway of microbial alicyclic acid metabolism.

\section{Metabolism of non-phenolic aromatic acids}

Urinary recovery of benzoic, phenylacetic, 3-phenylpropionic and cinnamic acids were similar after both rumen and abomasal infusion in the present experiments (see Table 5). Thus, exposure to the rumen microflora had little effect on the end products of metabolism of these acids. Although the anaerobic dissimilation of cyclohexanecarboxylic acid has been referred to previously these experiments do not suggest that aromatic acids undergo significant ring fission in the rumen. Balba \& Evans (1977 a) could not detect any conversion of benzoic to cyclohexanecarboxylic acid in rumen fluid cultures; furthermore, long induction periods with aromatic acids as the only $\mathrm{C}$ source were required before such cultures achieved a steady-state (Keith et al. 1978) of aromatic acid dissimilation.

Phenolic acids were not determined in the present experiments but there is little evidence that hydroxylation of the aromatic ring is a quantitatively significant pathway of aromatic acid metabolism in animal tissues. Acheson \& Gibbard (1962) found only $0.25 \%$ of benzoic acid to be hydroxylated and Bhatia et al. (1977), whilst finding some 3-methoxy, 4-hydroxycinnamic acid excretion on dosing rats with cinnamic acid, did not report quantitative results.

The almost complete urinary recovery of benzoic acid $(90 \%$; Table 5$)$ obtained following rumen infusion of this acid rules out the possibility that the low concentrations of benzoic acid found in rumen fluid (Fig. $1 b$ ) are a consequence of its rapid dissimilation in the rumen. However, the very variable concentration of benzoic acid found in rumen fluid when benzoic acid was infused into the rumen $(2-28 \mathrm{mg} / 1$; Fig. $1 \mathrm{~b}$ ) are not understood.

Rumen micro-organisms can use phenylacetic acid for phenylalanine biosynthesis (Allison, 1965; Martin, 1973). The urinary recoveries of infused phenylacetic acid found in Expt 4 do not suggest that this was a very extensive reaction (Table 5): lower urinary phenylacetic acid recovery would be expected on rumen infusion than on abomasal infusion if this were so. Whilst the recoveries are incomplete they are similar to those reported in other species (Scheline, 1978). No acids infused in Expts 5 or 6 (see Table 1) affected rumen phenylacetic acid concentration which showed a characteristic concentration change in relation to time after feeding (Fig. 1c): minimal concentrations were found between 4 and $9 \mathrm{~h}$ after feeding when rumen microbial growth may be expected to be rapid; just before the following feed and until significant digestion had occurred phenylacetic acid concentrations were much greater. At these times phenylacetic acid utilization for phenylalanine biosynthesis was either reduced or phenylalanine catabolism increased.

$\beta$-Oxidation of 3-phenylpropionic and cinnamic acids in body tissues is known to yield benzoic acid (Dakin, 1909). Therefore these acids were expected to be recovered in the urine as benzoic acid after both rumen and abomasal infusion (see Table 5). Whilst recovery of infused 3-phenylpropionic acid as urinary benzoic acid was complete this was not so with cinnamic acid: only $70 \%$ of the dose was recovered as urinary benzoic acid. Studies in other species (Scheline, 1978) have shown similarly incomplete recoveries of doses of cinnamic acid as urinary benzoic acid: the reasons for this are not known. Rumen 3-phenylpropionic acid concentration showed a trend opposite to that of phenylacetic acid in relation to time 


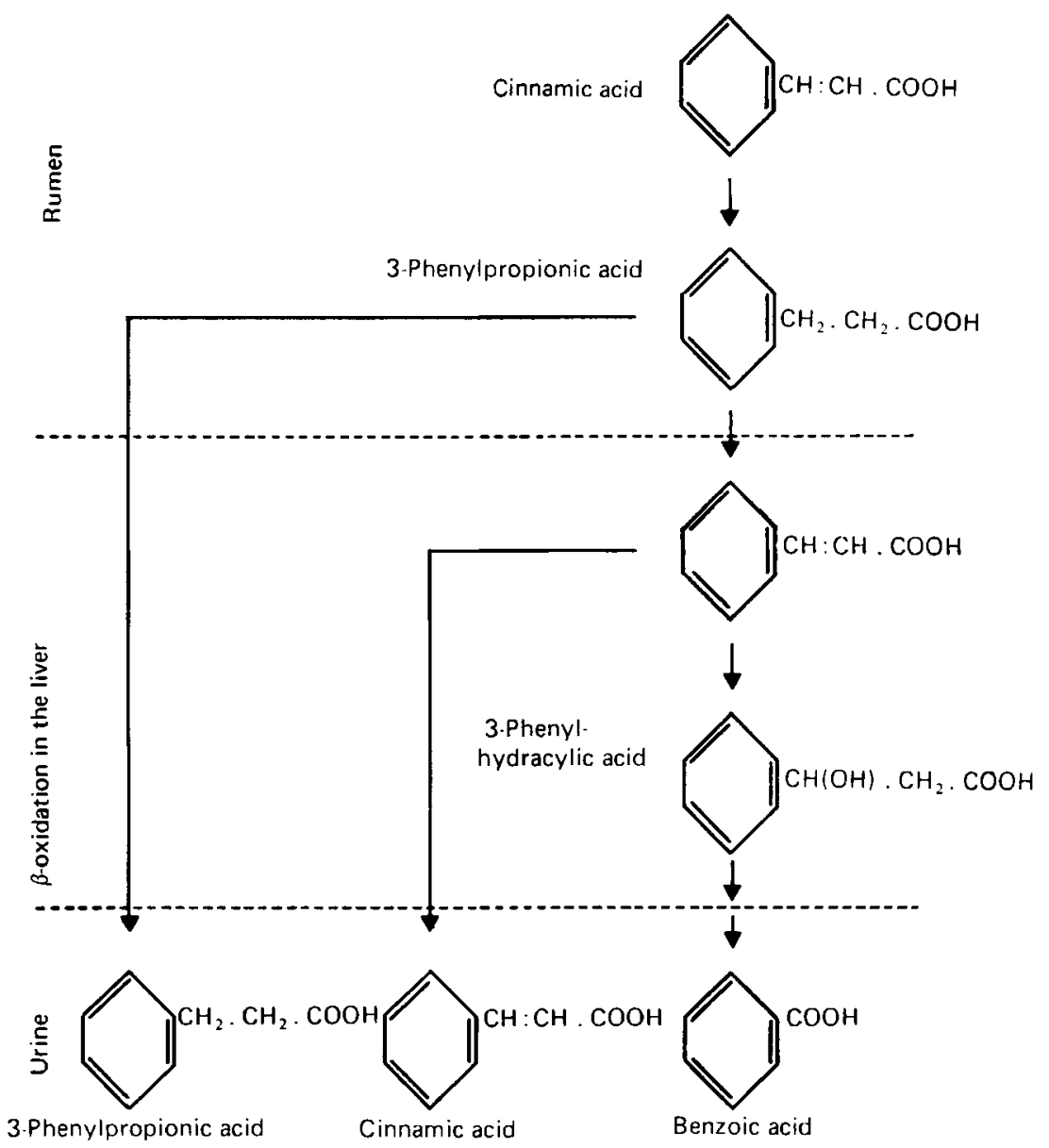

Fig. 2. The metabolism of cinnamic acid in the ruminant to yield benzoic acid as the principal urinary metabolite with small amounts of 3-phenylpropionic and cinnamic acids. The urinary acids are excreted as glycine conjugates (not shown). Phenylhydracrylic acid was not isolated in the present experiments.

of feeding: maximum concentrations were found between 4 and $6 \mathrm{~h}$ after feeding. When cinnamic acid was infused none was found in rumen fluid but the concentration of 3-phenylpropionic acid was increased by approximately $10 \mathrm{mg} B A E / 1$ rumen fluid per $\mathrm{g}$ BAE infused (Fig. 1d).

Cinnamic acid or 3-phenylpropionic acids or both were consistent minor components of the urinary aromatic acids found in these experiments (Tables 3 and 5). Usually the principal component of the cinnamic plus 3-phenylpropionic acid fraction was the former acid: it comprised (mean $\pm \mathrm{SD} ; n 187$ ) $81 \pm 12 \%$ of the acids in this fraction. Although intermediates in the $\beta$-oxidation of fatty acids are not readily observed in animal tissues (Stanley \& Tubbs, 1975), oxidation of phenyl-substituted acids appears to differ; Dakin (1909) found that dogs and cats excreted small amounts of doses of cinnamic acid and 3-phenylpropionic acids as cinnamic and 3-phenylhydracrylic acid (see Fig. 2). Dakin (1909) also noted that the proportion of the dose excreted as cinnamic acid varied widely in different animals: a feature also of the present studies (Table 3). Phenylhydracrylic acid was not found in the present experiments; it is a labile compound which readily loses water to yield cinnamic acid (Shaw \& Trevarthen, 1958) and may have been unstable to the hydrolysis conditions used in the 
present studies. Phenolic phenylhydracrylic acids (Wadman et al. 1973; Duncan et al. 1974) have been isolated from human urine when the $\beta$-oxidation pathway may have been overloaded: Pollitt (1974) offered a similar explanation for an unusually large urinary output of 3-phenylpropionic acid by a phenylketonuric patient. Williams \& Sweeley (1964) state that cinnamic acid is not found in mammalian urine. Its isolation in the present experiments suggests that microbial metabolism of dietary constituents to 3-phenylpropionic acid in the rumen followed by $\beta$-oxidation of this acid in the body tissues is responsible for the large quantities of urinary benzoic acid excreted by ruminants. The reactions involved are outlined in Fig. 2. These studies also suggest that compounds yielding 3-phenylpropionic acid in the rumen are more significant as aromatic acid precursors than are the alicyclic acids found in ruminant forages.

The author is indebted to Mrs J. T. Knox, Mr R. Miller and Mrs J. Quig for technical assistance. Mr C. Park was in charge of the experimental animals and Dr J. W. Czerkawski kindly provided facilities for the in vitro studies.

\section{REFERENCES}

Acheson, R. M. \& Gibbard, S. (1962). Biochim biophys. Acta 59, 320.

Adamson, R. H., Bridges, J. W., Evans, M. E. \& Williams, R. T. (1970). Biochem. J. $116,437$.

Allison. M. J. (1965). Biochem. biophys. Res. Commun. 18, 30.

Babior, B. M. \& Bloch K. (1966). J. biol. Chem. 241, 3643.

Balba, M. T. \& Evans, W. C. (1977a). Biochem. Soc. Trans. 5, 300.

Balba, M. T. \& Evans, W. C. (1977 b). Biochem. Soc. Trans. 5, 302.

Bhatia, I. S., Bajaj, K. L. \& Chakpravati, P. (1977). Indian J. exp. Biol. 15, 118.

Brewster, D., Jones, R. S. \& Parke, D. V. (1977). Biochem. J. 164, 595.

Brewster, D., Jones, R. S. \& Parke, D. V. (1978). Biochem. J. 170, 257.

Brigl, P. \& Pfähler, A. (1929). Tierernährung 1, 30.

Christie, W. W. (1974). Scan 4, 21.

Czerkawski, J. W. \& Breckenridge, G. (1969). Br. J. Nutr. 23, 51.

Dakin, H. D. (1909). J. biol. Chem. 6, 203.

Duncan, J. H., Couch, M. W., Gotthelf, G. \& Scott, K. N. (1974). Biomed. Mass Spectrom. 1, 40.

Halpern, M. J. (1960). Clinica chim. Acta 5, 264.

Indaht, S. R. \& Scheline, R. R. (1973). Xenobiotica 3, 549.

Keith, C. L., Bridges, R. L., Fina, L. R., Iverson, K. L. \& Cloran, J. A. (1978). Arch. Microbiol. $118,173$.

McEvoy-Bowe, E. (1966). Analyt. Biochem. 16, 153.

Martin, A. K. (1969a). Br. J. Nutr. 23, 389.

Martin, A. K. (1969b). Br. J. Nutr. 23, 715.

Martin, A. K. (1970). Br. J. Nutr. 24, 943.

Martin, A. K. (1973). Br. J. Nutr. 30, 251.

Mesnard, P. \& DeVaux, G. (1964). Bull. Soc. Chim. France 43.

Orpin, C. G. (1975). Proc. Soc. gen. Microbiol. 3, 12.

Patton, S. \& Kesler, E. M. (1967). J. Dairy Sci. 50, 1505.

Pazur, J. H. \& DeLong, W. H. (1948). Sci. Agric. 28, 39.

Pollitt, R. J. (1974). Clinica chim. Acta, 55, 317.

Scheline, R. R. (1978). Mammalian Metabolism of Plant Xenobiotics, pp. 170-228. London: Academic Press.

Schiemann, R., Zelck, U. \& Nehring, K. (1965). Arch. Tierernahr. $15,81$.

Scott, T. W., Ward, P. F. V. \& Dawson, R. M. C. (1964). Biochem. J. 90, 12.

Shaw, K. N. F. \& Trevarthen, J. (1958). Nature, Lond. 182, 797.

Stanley, K. K. \& Tubbs, P. K. (1975). Biochem. J. $150,77$.

Suemitsu, R., Fujita, S-I. \& Kamata, T. (1971). Agric. biol. Chem. 35, 1950.

Wadman, S. K., Van der Heiden, C., Ketting, D., Kamerling, J. P. \& Vliegenthart, J. F. G. (1973). Clinica chim. Acta. 47, 307.

Wainman, F. W. \& Paterson, D. (1963). J. agric. Sci., Camb. 61, 253.

Williams, C. M. \& Sweeley, C. C. (1964). In Biomedical Aspects of Gas Chromatography, p. 238 [H. A. Symanski, editor]. New York: Plenum Press. 